\section{Farmacogenómica como herramienta fundamental para la medicina personalizada: aplicaciones en la práctica clínica}

\author{
LUIS QUIÑONES $S^{1, a, f}$, ÁNGELA ROCO ${ }^{1,2,6, b}$, \\ JUAN P. CAYÚN ${ }^{1, c}$, PAULA ESCALANTE $E^{1, \mathrm{~d}}$, \\ CARLA MIRANDA ${ }^{1, b}$, NELSON VARELA $^{1, e, f, g,}$ \\ FRANCISCA MENESES ${ }^{3, e}$, BASTIÁN GALLEGOS ${ }^{3, e}$, \\ FAUSTO ZARUMA-TORRES ${ }^{4,5, c,}$, ISMAEL LARES-ASSEFF ${ }^{4}$
}

\section{Clinical applications of pharmacogenomics}

Pharmacogenomics is an emergent field aimed at tailoring pharmacological therapy. Genetic polymorphisms can modify the expression and function of enzymes and proteins involved in drug metabolism, affecting absorption, distribution, biotransformation and excretion as well as the drug-target interaction. Therefore, the presence of allelic variants will classify people as poor, extensive or rapid/ultra rapid metabolizers, modifying drug efficacy and safety. In this work, the state of art in relation to this discipline is presented and the genetic variants of enzymes that are involved in drug pharmacokinetics or pharmacodynamics are described. The effects of these variants on the therapeutic response to drugs used in our country are also discussed.

(Rev Med Chile 2017; 145: 483-500)

Key words: Pharmacogenetics; Pharmacokinetics; Pharmacogenomic variants; Polymorphisms, Genetic.

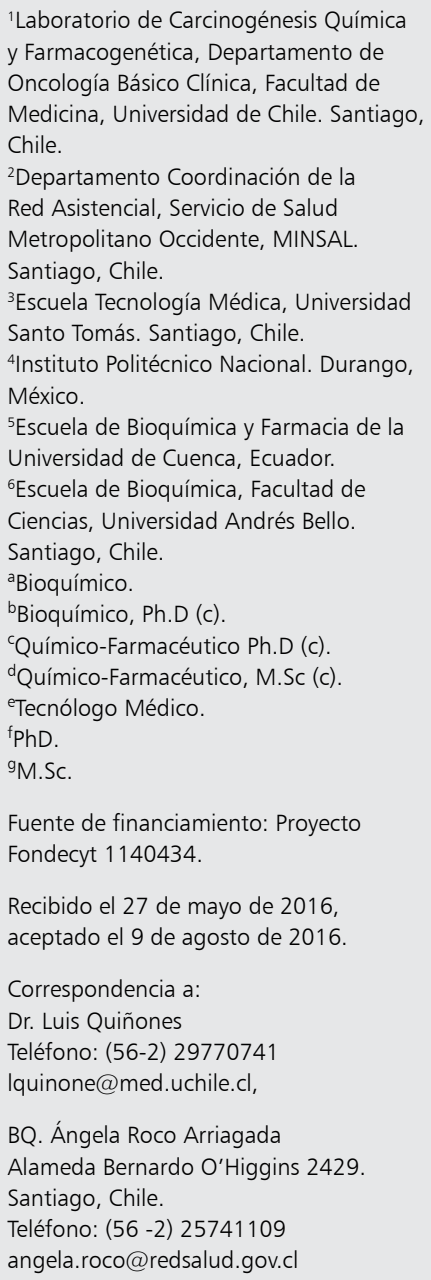

${ }^{5}$ Escuela de Bioquímica y Farmacia de la Universidad de Cuenca, Ecuador.

${ }^{6}$ Escuela de Bioquímica, Facultad de Ciencias, Universidad Andrés Bello.

BQ. Ángela Roco Arriagada Alameda Bernardo O'Higgins 2429. Santiago, Chile.

Teléfono: (56 -2) 25741109

angela.roco@redsalud.gov.cl

U $n$ hecho bien conocido es que los pacientes responden en forma diferente frente a la farmacoterapia y que ningún medicamento es $100 \%$ eficaz en todos los pacientes. Esta respuesta variable se debe, en gran medida, a factores genéticos, epigenéticos y ambientales, que afectan a las proteínas que metabolizan o transportan los fármacos, sus blancos terapéuticos (receptores) o ambos, influenciando tanto su eficacia como su seguridad, y en donde la contribución de cada factor varía en cada fármaco ${ }^{1-4}$. La Tabla 1 resume los factores que condicionan la variación interindividual en la respuesta a fármacos.

Debido al desarrollo de técnicas no invasivas de ingeniería genética y biología molecular y a la necesidad de encontrar una explicación a las variaciones en la respuesta a la acción de fármacos es que actualmente la farmacogenómica ha adquirido gran relevancia en la investigación farmacológica. Es así como los resultados de los del Proyectos Genoma Humano ${ }^{7}$, Internacional HapMap ${ }^{8} 1.000$ Genomas, el consorcio SNP ${ }^{9}$ y los estudios GWAS (Genome-Wide Association Studies) ${ }^{10}$ han aportado importantemente a nuestra comprensión de la variación genética humana ${ }^{5,11,12}$. Actualmente se sabe que existen 20.296 genes codificantes, 148.892.479 SNPs (polimorfismos de un solo nucleótido) y 4.363 .564 variantes estructurales 
Tabla 1. Factores que condicionan la variación interindividual en la respuesta a fármacos ${ }^{5,6}$

Fármaco
Calidad
Características fisicoquímicas, farmacocinéticas y
farmacodinámicas
Tipo de excipientes utilizados
Posología
Vía de administración
Interacción con otros fármacos
Paciente
Factores genéticos: eficacia transportadores, actividad
metabólica enzima, sensibilidad receptores
Factores epigenéticos: metilación de islotes CpG,
acetilación de histonas, expresión de miRNAs y otros
Factores fisiológicos: edad, sexo, embarazo-lactancia,
función renal y hepática
Factores patológicos: enfermedad renal, hepática u otra
Factores psicológicos: efecto placebo
Ambiente
Dieta: consumo de cafeína, carne, vegetales
Ingesta de alcohol
Humo de cigarrillo
Agentes contaminantes

CpG: sitios ricos en Citosina y Guanina. miRNA: micro RNA (ácido ribonucleico)

(inserciones, deleciones, duplicaciones, translocaciones, re-arreglos cromosómicos complejos, entre otros $)^{13}$. De este modo, sus resultados han sido importantes insumos para la individualización de la farmacoterapia y modelos predictivos para el desarrollo de las primeras 35 Guías Clínicas Farmacogenómicas ${ }^{14}$.

De acuerdo a lo anterior, este trabajo busca mostrar una visión general acerca del área y la posibilidad de utilizar y aplicar, en la consulta clínica diaria, herramientas farmacogenéticas para mejorar la eficacia y seguridad del tratamiento farmacológico.

\section{Variabilidad, farmacogenómica y medicina personalizada}

Ya en el año 1892 Sir William Osler señaló: "Si no fuera por la gran variabilidad entre los individuos, la medicina podría ser considerada una ciencia, no un arte", y en 1895 el Dr. Claude Bernard señaló "la excesiva complejidad de los procesos fisiológicos y organismos donde se observan impone el respeto a la idea que no hay dos pacientes iguales". Ambas frases refuerzan la idea que la variabilidad no es un problema nuevo y que es necesario individualizar los tratamientos.

Desde la primera publicación científica en farmacogenómica, justo después que el farmacólogo alemán Friedrich Vogel acuñara la palabra ${ }^{15}$, ha habido un explosivo aumento en el número de artículos de investigación, revistas científicas del área y ensayos clínicos con base farmacogenómi$\mathrm{ca}^{16}$. Estos estudios farmacogenéticos/farmacogenómicos están dirigidos a identificar variantes génicas o productos génicos que pueden modificar la magnitud del efecto farmacológico y los efectos secundarios e interacciones droga-droga ${ }^{5,6,17-19}$.

El objetivo más ambicioso de la farmacogenómica es poder definir el tratamiento farmacológico personalizado según el perfil genético de cada paciente, idea base para el concepto de Medicina Personalizada. El hallazgo de nuevos biomarcadores genéticos de susceptibilidad y respuesta a medicamentos pone a disposición de los profesionales de la salud, herramientas para tomar decisiones informadas respecto al mejor tratamiento en un paciente determinado, posologías adecuadas, evitar reacciones adversas y desarrollar nuevas drogas según el perfil genético-metabólico de los pacientes ${ }^{20-22}$.

\section{Aplicaciones de la farmacogenómica en la clínica}

Extensas investigaciones se han llevado a cabo para encontrar biomarcadores genéticos asociados con la susceptibilidad, el diagnóstico, el pronóstico de la enfermedad y la respuesta al tratamiento. Para este objetivo, los estudios han utilizado una aproximación mediante genes candidatos y estudios de asociación del genoma completo. Es interesante observar que los estudios de genes candidatos farmacogenómicos han sido sustancialmente más exitosos en identificar variantes polimórficas con un impacto clínicamente significativo y reproducible (p. ej. variantes de CYP2C9 y farmacocinética de warfarina y acenocumarol), en comparación con las investigaciones de genes candidatos de susceptibilidad a una enfermedad en particular. Esto se debe posiblemente a que existe 
una mayor comprensión de las vías metabólicas de un fármaco, en comparación con complejos procesos que influyen en el desarrollo de una enfermedad $^{21,23}$.

A pesar de las altas expectativas, la transferencia de las asociaciones genéticas a la práctica clínica ha sido lenta, con algunas excepciones notables, tales como la identificación del genotipo HLA-B ${ }^{\star} 57: 01$ antes de administrar la terapia anti-retroviral abacavir, variante que aumenta significativamente la hipersensibilidad al medicamento $^{24}$. Otra excepción notable sucede en el ámbito de la oncología, donde hay un creciente arsenal de terapias genotipo-dependientes con licencia. Por ejemplo, el tamoxifeno está indicado sólo en las pacientes con cáncer de mama con receptores de estrógenos positivos. Más recientemente vemurafenib, aprobado para el tratamiento del melanoma no resecable o metastásico, actúa cuando está presente la mutación BRAF E600, pero no el tipo silvestre (BRAF V600).

Si bien la farmacogenética ha encontrado un extenso campo de aplicación en la oncología, también se ha evaluado su aplicación en otras áreas terapéuticas, como la analgesia, psiquiatría, cardiología y neurología, entre otras ${ }^{6,16,24-26}$.

\section{Biotransformación/metabolismo de fármacos}

El desarrollo de la farmacogenómica a nivel mundial se ha realizado sobre la base del conocimiento de las reacciones de biotransformación (fase 1 y 2) de medicamentos, llevadas a cabo por enzimas de naturaleza muy diversa, entre las que destacan los citocromo P450 (CYP450), sin duda el miembro más importante y más estudiado de enzimas de fase $1^{27,28}$. Para estas enzimas se ha diseñado una nomenclatura estándar utilizando la raíz CYP seguido de un número arábigo que designa la familia de enzimas, una letra para designar la subfamilia y otro número que denota la enzima individual, por ejemplo, CYP2C1929. Para cada enzima el alelo silvestre se designa como ${ }^{\star} 1$ y las variantes alélicas se numeran de manera secuencial según han sido identificadas $\left({ }^{\star} 2,{ }^{\star} 3 \text {, etc. }\right)^{30}$. Es por estas variantes que la respuesta farmacológica o la susceptibilidad a la acción de tóxicos varía extraordinariamente entre diferentes individuos ${ }^{31}$ (ver detalle en http://www.cypalleles.ki.se/).

Dentro de las enzimas más relevantes de fase 2, se encuentran las glutatión S-transferasas (GSTs),
N-Acetiltransferasas, UDP-Glucuroniltransferasas (UGT o UDPGT), Sulfotranferasas y Metiltransferasas, tales como Tiopurinas S-Metiltransferasas (TPMT) y Catecol-O-Metiltransferasas (COMT). Todas ellas presentan variantes alélicas que también se asocian a reacciones adversas a medicamentos ${ }^{32-34}$.

Los polimorfismos genéticos (variaciones genéticas) que se presentan en las enzimas de las fases 1 y 2 pueden generar profundos cambios en la actividad enzimática final, afectando los niveles plasmáticos de fármacos y clasificando a las personas como metabolizadores pobres, lentos, normales/extensivos o rápidos/ultrarrápidos ${ }^{35-37}$.

Pese a esto, la genética por sí sola no puede explicar la variabilidad interindividual que existe en la respuesta farmacológica. Es por ello que recientemente, el campo de la fármaco-epigenética está estudiando nuevos factores que podrían influir en este aspecto (p.ej. microRNAs, metilación de genes, etc. $)^{38-40}$.

\section{Farmacogenómica de los blancos terapéuticos}

Por otro lado, el principio de variabilidad también radica en que los blancos terapéuticos pueden ser biomarcadores farmacodinámicos por presentar variantes genéticas en población, llevando a diferencias en la eficacia farmacológica. Entre estos biomarcadores podemos destacar un par de ejemplos notables:

1. Vitamina K epóxido reductasa (VKOCR): Enzima blanco de acción de los fármacos anticoagulantes cumarínicos (acenocumarol y warfarina), responsable de la renovación de la vitamina $K$ oxidada y que es un cofactor esencial para la activación de la cascada de la coagulación. El polimorfismo VKORC1 (-1639G > A -rs9923231-), reduce la unión de factores de transcripción y el efecto final es una menor cantidad de enzima, requiriéndose dosis menores de warfarina o acenocumarol para obtener el efecto farmacológico deseado ${ }^{41}$.

2. Timidilato sintasa (TYMS): Enzima blanco de acción de fluorouracilo que genera la conversión monofosfato de desoxiuridina, cuya conversión es fundamental para generar timidina para la síntesis de DNA. Polimorfismos en este gen afectan el tratamiento de quimioterapias con 5-fluorouracilo (5FU) ${ }^{42,43}$. 
En la Tabla 2 se muestran los polimorfismos de enzimas de biotransformación de Fase 1 y Fase 2 y en la Tabla 3 para biomarcadores farmacodinámicos, para los cuales existe un consenso en las recomendaciones de dosificación y prescripción.

\section{Proteínas transportadoras de fármacos}

Un capítulo aparte lo constituyen los transportadores de drogas, que juegan un importante papel en los procesos de absorción, distribución y excreción de los medicamentos. En este sentido, es indudable la importancia de los transportadores ABC (ATP-binding-cassette), cuya misión es la de exportar compuestos desde el interior al exterior de las células. El transportador más estudiado es la glicoproteína-P, codificada por el gen $\mathrm{ABCB} 1$ (o MDR1), cuya expresión en varios tejidos normales sugiere su importante papel en la excreción de metabolitos a la orina, bilis y lumen intestinal, mientras que en la barrera hemato-encefálica limita la acumulación de varias drogas en el cerebro. Polimorfismos tales como $3435 \mathrm{C}>\mathrm{T}$ o $2677 \mathrm{G}>\mathrm{T}$ en dicho gen se asocian a modificaciones en la concentración de los fármacos y causan desde efectos indeseables a falta de acción terapéutica. Del mismo modo, el papel de polimorfismos genéticos en otros transportadores como MRPs (multidrug-resistance proteins), OATs (organic anion-transporters), SCL (solute carrier) y OCTs (organic cation transporters), entre otros, han sido ampliamente investigados, con resultados muy prometedores ${ }^{45-50}$. En la Tabla 4 se muestran los polimorfismos conocidos en la actualidad para transportadores de fármacos potencialmente útiles en la personalización fármaco-terapéutica.

\section{FDA y aplicación clínica de la farmacogenómica}

Actualmente la FDA (Food and Drug administration), ha acogido la validación y aprobación de biomarcadores farmacogenéticos para ser utilizados en la práctica clínica. A la fecha se sugieren 178 biomarcadores $^{51}$, incluyendo la información necesaria para hacer uso de éstos con el fin de realizar un ajuste de concentraciones de medicamentos. Por ejemplo, se recomienda análisis farmacogenético para pacientes tratado con maraviroc, cetuximab, trastuzumab y dasatinib, con objeto de disminuir posibles efectos no deseados ${ }^{52-54}$. En la Tabla 5 se muestran fármacos y sus biomarcadores farmacogenómicos actualmente sugeridos por la FDA para uso en la práctica clínica.

Sin perjuicio de lo anterior, en Estados Unidos de Norteamérica existe controversia, pues algunos médicos utilizan la farmacogenómica en su trabajo diario y afirman que es una herramienta de gran utilidad para mayor eficacia y seguridad de medicamentos, en cambio, otro grupo de médicos, no recomiendan aún su aplicación acusando falta de conocimiento acabado del área. En un estudio realizado entre los años 2011-2012, en Estados Unidos de Norteamérica, los autores concluyeron que existe deficiencia en el conocimiento de la farmacogenómica en la práctica clínica, sobre todo en poblaciones rurales. Otros estudios señalan que menos de 13\% de los médicos solicita la realización de pruebas farmacogenómicas en su quehacer diario ${ }^{55}$. En América Latina obtuvimos resultados similares en un estudio realizado en 9 países, observando que existe una subestimación de la utilidad de los genes polimórficos asociados a medicamentos en comparación con resultados de encuestas realizadas en Estados Unidos de Norteamérica y España. En estos estudios hubo coincidencia tan sólo en la utilidad de tres biomarcadores farmacogenómicos ${ }^{16}$.

Hoy en día, el Consorcio para la Implementación de la Farmacogenética en la Clínica (CPIC) junto a la red de investigación farmacogenómica (PGRN), persiguen como objetivo generar guías que faciliten la interpretación de las pruebas farmacogenómicas de laboratorio y así proporcionar ayuda al médico en la prescripción de medicamen$\operatorname{tos}^{53,56}$. Actualmente este consorcio ha desarrollado 35 guías (al 20 de diciembre de 2015), divulgadas en el sitio web de PharmGKB ${ }^{14}$.

Además, recientemente se han desarrollado diferentes plataformas web, las que disponen de información almacenada en su base de datos (genes, variantes alélicas y dosificaciones de medicamentos según genotipo), con el fin de servir como uso de investigación o como orientación a médicos en la aplicación de la farmacogenómica en la práctica clínica (Tabla 6). 


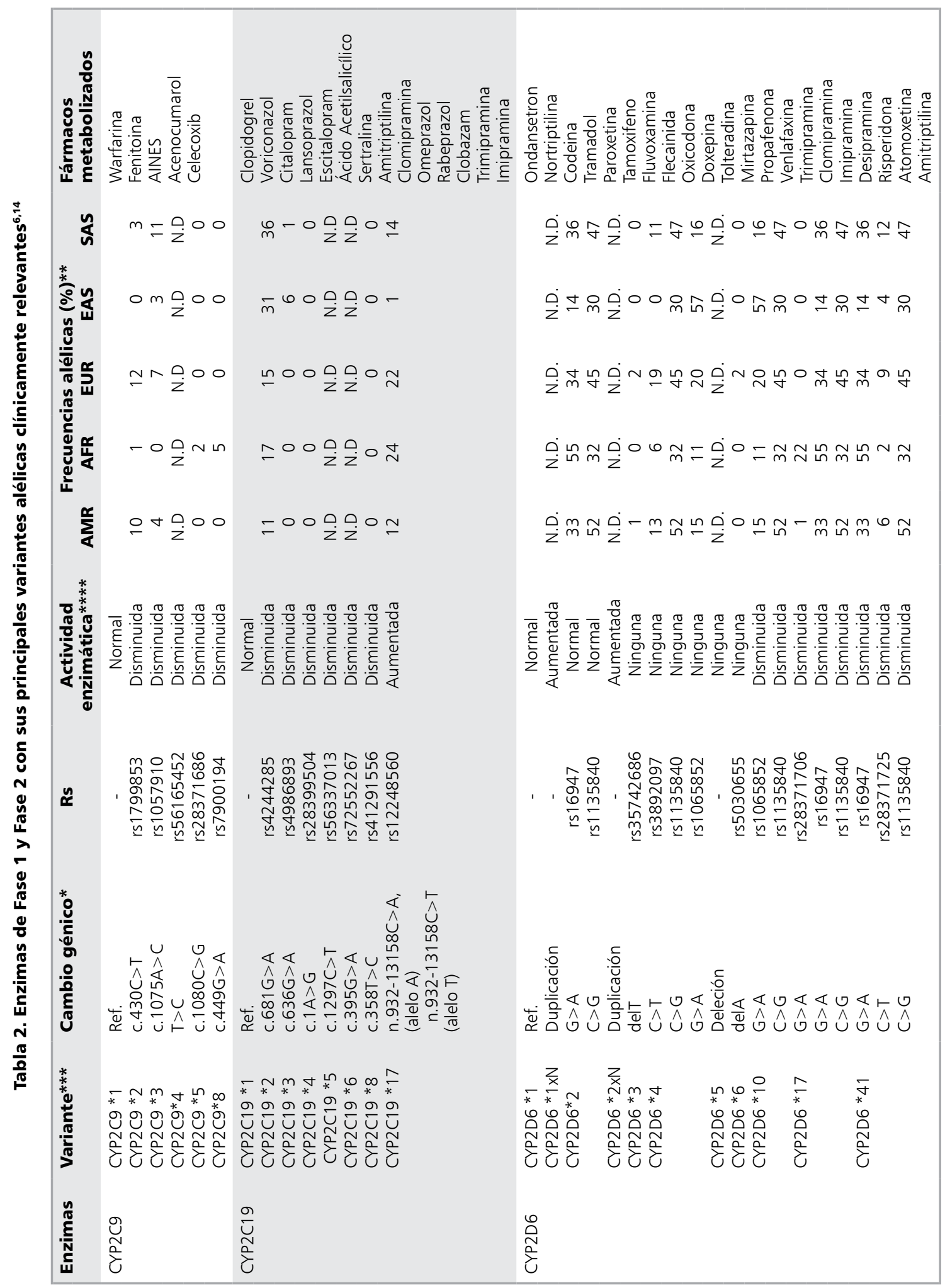




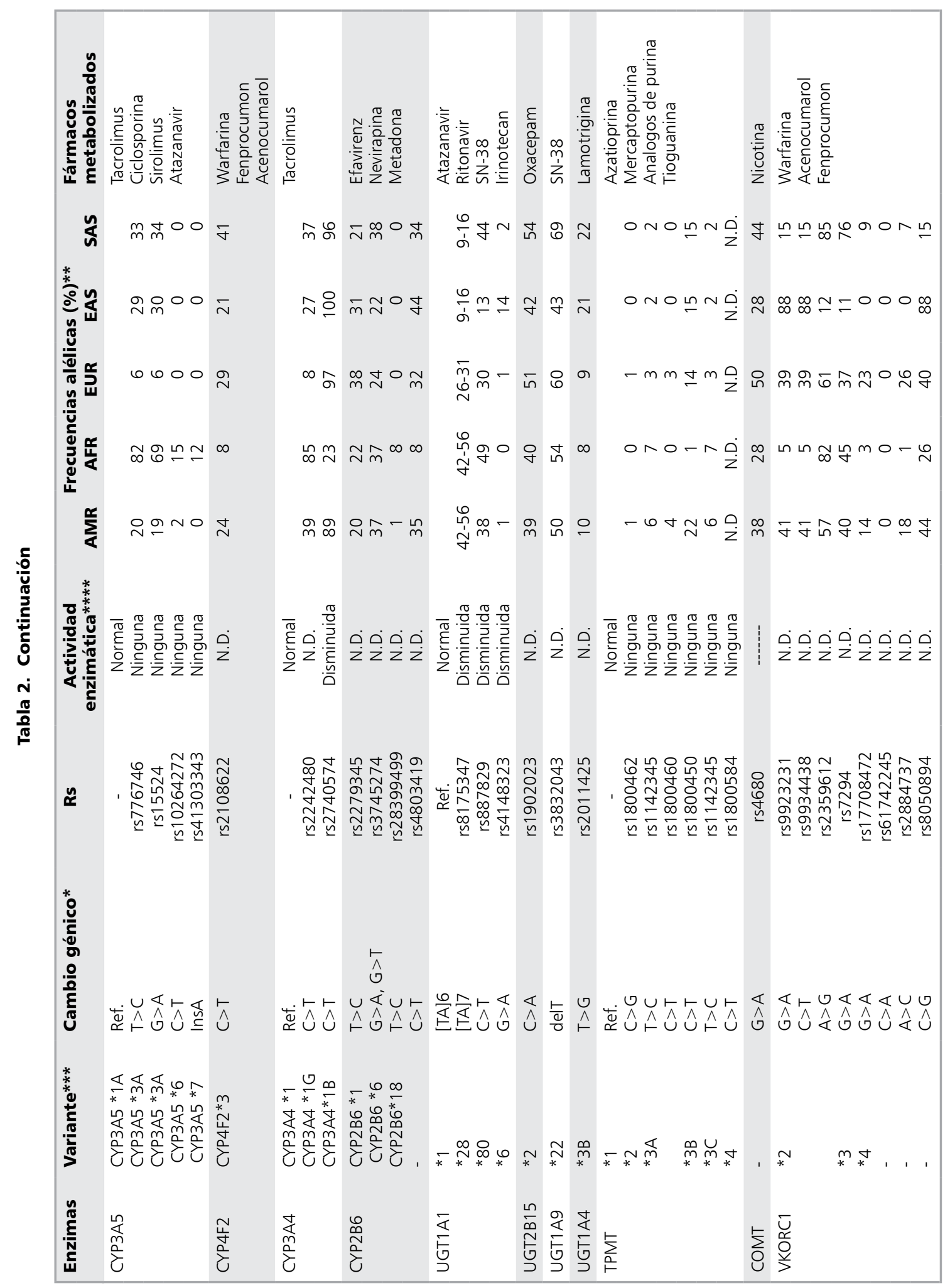




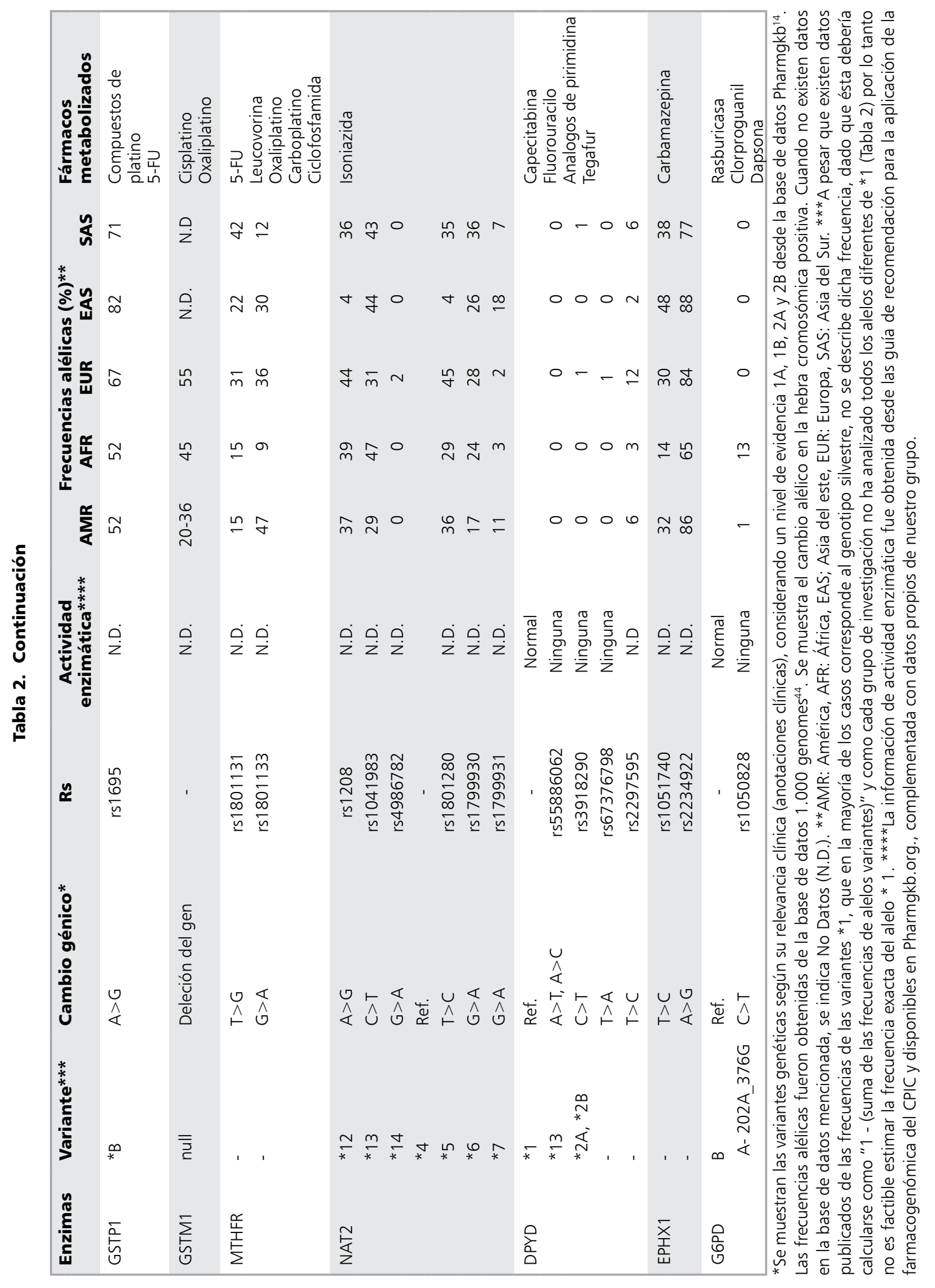




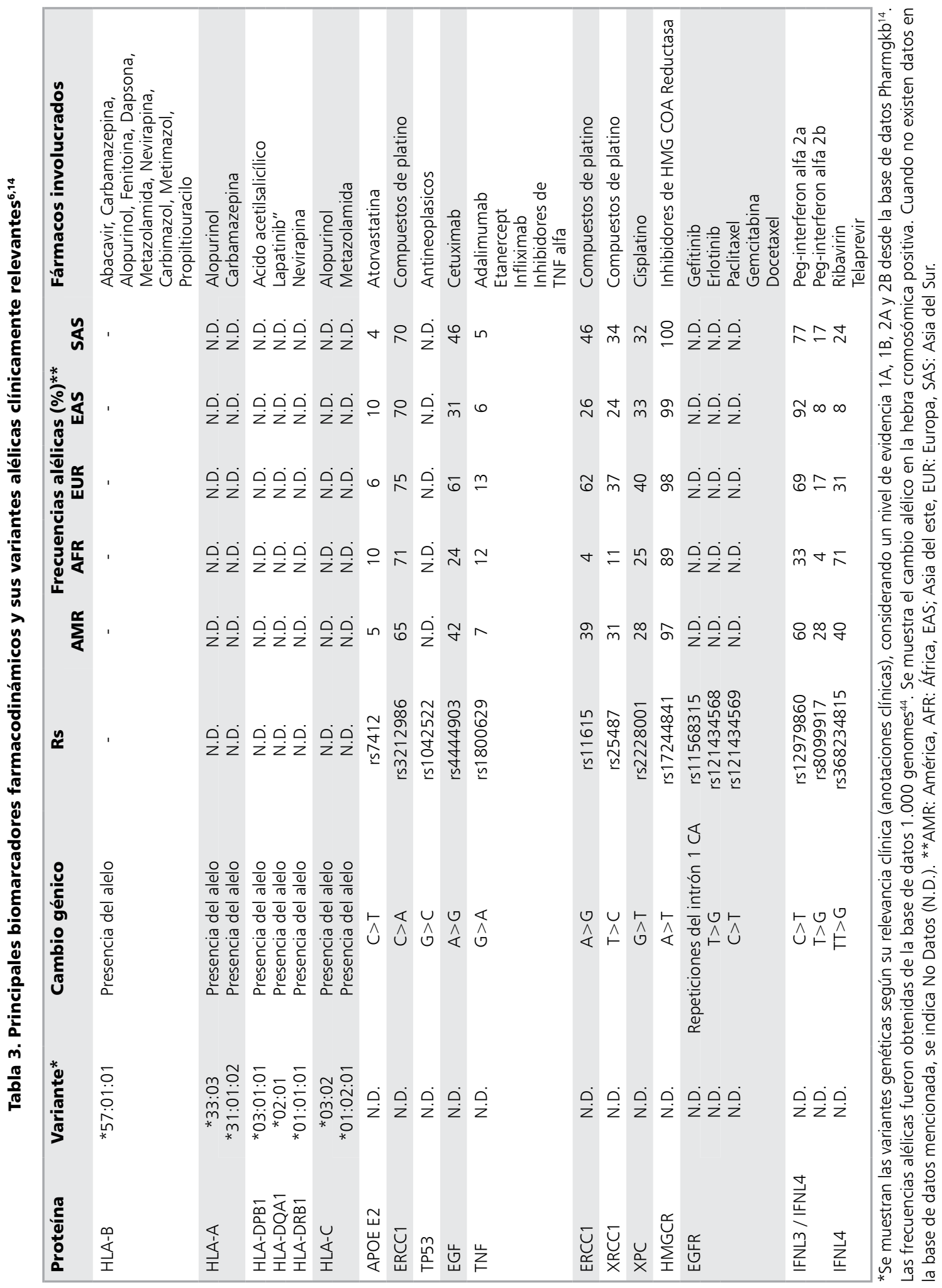


Farmacogenómica, medicina personalizada y la práctica clínica - L. Quiñones et al

Tabla 4. Transportadores de fármacos y sus variantes alélicas clínicamente relevantes ${ }^{14}$

\begin{tabular}{|c|c|c|c|c|c|c|c|c|c|}
\hline \multirow[t]{2}{*}{ Transportador } & \multirow[t]{2}{*}{ Variante* } & \multirow{2}{*}{$\begin{array}{l}\text { Cambio } \\
\text { génico }\end{array}$} & \multirow[t]{2}{*}{ Rs } & \multicolumn{5}{|c|}{ Frecuencias alélicas $(\%) * *$} & \multirow{2}{*}{$\begin{array}{l}\text { Fármacos } \\
\text { transportados }\end{array}$} \\
\hline & & & & AMR & AFR & EUR & EAS & SAS & \\
\hline \multirow[t]{11}{*}{$A B C B 1$} & N.D & $A>T, A>G$ & rs1045642 & 43 & 15 & 52 & 40 & 57 & \multirow{11}{*}{$\begin{array}{l}\text { Digoxina } \\
\text { Nevirapina } \\
\text { Metotrexato } \\
\text { Ondansetrón } \\
\text { Fentanilo } \\
\text { Metadona } \\
\text { Morfina } \\
\text { Opioides } \\
\text { Oxicodona } \\
\text { Tramadol } \\
\text { Simvastatina } \\
\text { Ondansetrón }\end{array}$} \\
\hline & N.D & $A>T, A>C$ & rs2032582 & $A: 37$ & $A: 2$ & $A: 41$ & $A: 40$ & $A: 59$ & \\
\hline & & & & $\mathrm{T}: 6$ & $\mathrm{~T}: 0$ & $\mathrm{~T}: 2$ & $\mathrm{~T}: 13$ & $\mathrm{~T}: 5$ & \\
\hline & & & & & & & & & \\
\hline & & & & & & & & & \\
\hline & & & & & & & & & \\
\hline & & & & & & & & & \\
\hline & & & & & & & & & \\
\hline & & & & & & & & & \\
\hline & & & & & & & & & \\
\hline & & & & & & & & & \\
\hline $\mathrm{ABCC} 4$ & N.D & $C>T$ & rs1751034 & 25 & 27 & 19 & 22 & 10 & Tenofovir \\
\hline ABCG2 & N.D & $\mathrm{G}>\mathrm{T}$ & rs2231142 & 14 & 1 & 9 & 29 & 10 & Rosuvastatina \\
\hline \multirow[t]{4}{*}{ SLCO1B1 } & N.D & $G>A$ & rs4149015 & 4 & 1 & 6 & 13 & 4 & \multirow{4}{*}{$\begin{array}{l}\text { Inhibidores } \\
\text { de HMG CoA } \\
\text { reductasa }\end{array}$} \\
\hline & $* 1 \mathrm{~B}$ & $A>G$ & rs2306283 & 53 & 18 & 60 & 24 & 45 & \\
\hline & \multirow[t]{2}{*}{ *15 } & $A>G$ & rs2306283 & 53 & 18 & 60 & 24 & 45 & \\
\hline & & $\mathrm{T}>\mathrm{C}$ & rs4149056 & 13 & 1 & 16 & 12 & 4 & \\
\hline SLC47A2 & N.D & $G>A$ & rs12943590 & 32 & 18 & 27 & 45 & 40 & Metformina \\
\hline \multirow[t]{2}{*}{ SLC6A4 } & N.D & $\begin{array}{l}\text { Alelo S (forma } \\
\text { corta HTTLPR) }\end{array}$ & - & N.D. & N.D. & N.D. & N.D. & N.D. & \multirow[t]{2}{*}{$\begin{array}{l}\text { Escitalopram } \\
\text { Citalopram }\end{array}$} \\
\hline & & $\begin{array}{l}\text { Alelo L (forma } \\
\text { larga HTTLPR) }\end{array}$ & - & N.D. & N.D. & N.D. & N.D. & N.D. & \\
\hline
\end{tabular}

*Se muestran las variantes genéticas según su relevancia clínica (anotaciones clínicas), considerando un nivel de evidencia 1A, 1B, 2A y 2B desde la base de datos Pharmgkb ${ }^{14}$. Las frecuencias alélicas fueron obtenidas de la base de datos 1.000 genomes $^{44}$. Se muestra el cambio alélico en la hebra cromosómica positiva. Cuando no existen datos en la base de datos mencionada, se indica No Datos (N.D.) **AMR: América, AFR: África, EAS; Asia del este, EUR: Europa, SAS: Asia del sur.

Tabla 5. Fármacos y biomarcadores farmacogenómicos sugeridos por la US-FDA ${ }^{51}$

\begin{tabular}{|c|c|c|c|}
\hline Fármaco & Área terapéutica & Biomarcador & Subgrupo referencia \\
\hline Abacavir & Enfermedad infecciosa & HLA-B & Alelos portadores HLA-B*5701 \\
\hline Ado-Trastuzumab Emtansine & Oncología & ERBB2 & $\begin{array}{l}\text { Sobreexpresión proteína HER2 o amplificación } \\
\text { del gen }\end{array}$ \\
\hline Afatinib & Oncología & EGFR & $\begin{array}{l}\text { EGFR exón } 19 \text { deleción o exón } 21 \text { sustitución } \\
\text { (L858R) positiva }\end{array}$ \\
\hline Amitriptilina & Psiquiatría & CYP2D6 & CYP2D6 Metabolizador pobre \\
\hline Anastrozol & Oncología & ESR1, PGR & Receptor hormona positivo \\
\hline Arformoterol & Pulmonar & UGT1A1 & UGT1A1 Metabolizador pobre \\
\hline Arformoterol & Pulmonar & CYP2D6 & CYP2D6 Metabolizador intermedio o pobre \\
\hline Aripiprazol & Psiquiatría & CYP2D6 & CYP2D6 Metabolizador pobre \\
\hline Trióxido Arsénico & Oncología & PML-RARA & PML-RAR $\alpha$ Translocación positiva \\
\hline Atomoxetina & Psiquiatría & CYP2D6 & CYP2D6 Metabolizador pobre \\
\hline Azatioprina & Reumatología & TPMT & TPMT Metabolizador intermedio o pobre \\
\hline Boceprevir & Enfermedad infecciosa & IFNL3 & $\begin{array}{l}\text { IL28B rs12979860 T alelo portador (genotipo } \\
\text { C/T y T/T) }\end{array}$ \\
\hline
\end{tabular}


Tabla 5. Fármacos y biomarcadores farmacogenómicos sugeridos por la US-FDA ${ }^{51}$

\begin{tabular}{|c|c|c|c|}
\hline Fármaco & Área terapéutica & Biomarcador & Subgrupo referencia \\
\hline Bosutinib & Oncología & BCR/ABL1 & Cromosoma Filadelfia positivo \\
\hline Busulfán & Oncología & BCR-ABL1 & Cromosoma Philadelphia negativo \\
\hline Capecitabina & Oncología & DPYD & Deficiencia de DPD \\
\hline Carbamazepina & Neurología & $\begin{array}{l}\text { HLA-B } \\
\text { HLA-A }\end{array}$ & $\begin{array}{l}\text { Alelo portador HLA-B*1502 } \\
\text { Alelo portador HLA-A*3101 }\end{array}$ \\
\hline Ácido Carglúmico & $\begin{array}{l}\text { Errores intrínsecos del } \\
\text { metabolismo }\end{array}$ & NAGS & Deficiencia N-acetilglutamato sintetasa \\
\hline Carisoprodol & Reumatología & CYP2C19 & CYP2C1 Metabolizador pobre \\
\hline Carvedilol & Cardiología & CYP2D6 & CYP2D6 Metabolizador pobre \\
\hline Celecoxib & Reumatología & CYP2C9 & CYP2C9 Metabolizador pobre \\
\hline Ceritinib & Oncología & ALK & ALK Reordenamiento gen \\
\hline Cetuximab & Oncología & $\begin{array}{l}\text { EGFR } \\
\text { KRAS }\end{array}$ & $\begin{array}{l}\text { EGFR Expresión proteína positiva } \\
\text { KRAS codon } 12 \text { y } 13 \text { mutación negativa }\end{array}$ \\
\hline Cevimelina & Dental & CYP2D6 & CYP2D6 Metabolizador pobre \\
\hline Cloroquina & Enfermedad infecciosa & G6PD & Deficiencia G6PD \\
\hline Clorpropamida & Endocrinología & G6PD & Deficiencia G6PD \\
\hline Cisplatin & Oncología & TPMT & TPMT Metabolizador intermedio o pobre \\
\hline Citalopram & Psiquiatría & $\begin{array}{l}\text { CYP2C19 } \\
\text { CYP2D6 }\end{array}$ & $\begin{array}{l}\text { CYP2C19 Metabolizador pobre } \\
\text { CYP2D6 Metabolizador pobre }\end{array}$ \\
\hline Clobazam & Neurología & CYP2C19 & CYP2C19 Metabolizador pobre \\
\hline Clomipramina & Psiquiatría & CYP2D6 & CYP2D6 Metabolizador pobre \\
\hline Clopidogrel & Cardiología & CYP2C19 & CYP2C19 Metabolizador intermedio o pobre \\
\hline Clozapina & Psiquiatría & CYP2D6 & CYP2D6 Metabolizador pobre \\
\hline Codeína & Anestesiología & CYP2D6 & CYP2D6 Metabolizador ultra-rápido \\
\hline Crizotinib & Oncología & ALK & ALK Reordenamiento gen \\
\hline Dabrafenib & Oncología & $\begin{array}{l}\text { BRAF } \\
\text { G6PD }\end{array}$ & $\begin{array}{l}\text { BRAF V600E/K Mutación positiva } \\
\text { Deficiencia G6PD }\end{array}$ \\
\hline Dapsona & $\begin{array}{l}\text { Dermatología } \\
\text { Enfermedad infecciosa }\end{array}$ & $\begin{array}{l}\text { G6PD } \\
\text { G6PD }\end{array}$ & $\begin{array}{l}\text { Deficiencia G6PD } \\
\text { Deficiencia G6PD }\end{array}$ \\
\hline Dasatinib & Oncología & BCR/ABL1 & $\begin{array}{l}\text { Cromosoma Filadelfia positivo, T315I mutación } \\
\text { positiva }\end{array}$ \\
\hline Denileukin Diftitox & Oncología & IL2RA & CD25 Antígeno positivo \\
\hline Desipramina & Psiquiatría & CYP2D6 & CYP2D6 Metabolizador pobre \\
\hline Dexlansoprazol & Gastroenterología & CYP2C19 & CYP2C19 Metabolizador pobre \\
\hline $\begin{array}{l}\text { Dextrometorfano y } \\
\text { Quinidina }\end{array}$ & Neurología & CYP2D6 & CYP2D6 Metabolizador pobre \\
\hline Diazepam & Psiquiatría & CYP2C19 & CYP2C19 Metabolizador pobre \\
\hline Divalproex & Neurología & POLG & POLG Mutación positivo \\
\hline Doxepina & Psiquiatría & $\begin{array}{l}\text { CYP2D6 } \\
\text { CYP2C19 }\end{array}$ & $\begin{array}{l}\text { CYP2D6 Metabolizador pobre } \\
\text { CYP2D6 Metabolizador pobre }\end{array}$ \\
\hline $\begin{array}{l}\text { Drospirenona } \\
\text { Etinil Estradiol }\end{array}$ & $\begin{array}{l}\text { Ginecología, } \\
\text { Dermatología }\end{array}$ & CYP2C19 & CYP2C19 Metabolizador intermedio \\
\hline Eliglustat & $\begin{array}{l}\text { Errores intrínsecos del } \\
\text { metabolismo }\end{array}$ & CYP2D6 & $\begin{array}{l}\text { CYP2D6 Metabolizador intermedio, pobre y } \\
\text { ultra-rápido. }\end{array}$ \\
\hline Eltrombopag & Hematología & $\begin{array}{l}\text { F5 } \\
\text { SERPINC1 }\end{array}$ & $\begin{array}{l}\text { Portador Factor V Leiden } \\
\text { Deficiencia Antitrombina III }\end{array}$ \\
\hline
\end{tabular}


Farmacogenómica, medicina personalizada y la práctica clínica - L. Quiñones et al

Tabla 5. Continuación

\begin{tabular}{|c|c|c|c|}
\hline Fármaco & Área terapéutica & Biomarcador & Subgrupo referencia \\
\hline Erlotinib & Oncología & $\begin{array}{l}\text { EGFR } \\
\text { EGFR }\end{array}$ & $\begin{array}{l}\text { EGFR Expresión proteína positiva } \\
\text { EGFR exón } 19 \text { deleción o exón } 21 \text { sustitución } \\
\text { (L858R) positivo }\end{array}$ \\
\hline Esomeprazol & Gastroenterología & CYP2C19 & CYP2C19 Metabolizador pobre \\
\hline Everolimus & Oncología & $\begin{array}{l}\text { ERBB2 } \\
\text { ESR1 }\end{array}$ & $\begin{array}{l}\text { HER2 Sobrexpresión proteína negativo } \\
\text { Receptor de estrógeno positivo }\end{array}$ \\
\hline Exemestano & Oncología & $\begin{array}{l}\text { ESR1 } \\
\text { PGR }\end{array}$ & $\begin{array}{l}\text { Receptor de estrógeno positivo } \\
\text { Receptor progesterona positivo }\end{array}$ \\
\hline Fluorouracilo (5-FU) & $\begin{array}{l}\text { Dermatología } \\
\text { Oncología }\end{array}$ & $\begin{array}{l}\text { DPYD } \\
\text { DPYD }\end{array}$ & $\begin{array}{l}\text { Deficiencia DPD } \\
\text { Deficiencia DPD }\end{array}$ \\
\hline Fluoxetina & Psiquiatría & CYP2D6 & CYP2D6 Metabolizador pobre \\
\hline Flurbiprofeno & Reumatología & CYP2C9 & CYP2C9 Metabolizador pobre \\
\hline Fluvoxamina & Psiquiatría & CYP2D6 & CYP2D6 Metabolizador pobre \\
\hline Fulvestrant & Oncología & ESR1, PGR & Receptor hormona positivo \\
\hline Galantamina & Neurología & CYP2D6 & CYP2D6 Metabolizador pobre \\
\hline Glimepirida & Endocrinología & G6PD & Deficiencia G6PD \\
\hline Glipizida & Endocrinología & G6PD & Deficiencia G6PD \\
\hline Gliburida & Endocrinología & G6PD & Deficiencia G6PD \\
\hline Ibrutinib & Oncología & del $(17 p)$ & Cromosoma 17p deleción positiva \\
\hline Iloperidona & Psiquiatría & CYP2D6 & CYP2D6 Metabolizador pobre \\
\hline \multirow[t]{4}{*}{ Imatinib } & \multirow[t]{4}{*}{ Oncología } & KIT & $\begin{array}{l}\text { KIT Expresión proteína positiva, c-KIT D816V } \\
\text { mutación negativa }\end{array}$ \\
\hline & & BCR-ABL1 & Cromosoma Filadelfia positivo \\
\hline & & PDGFRB & PDGFR Reordenamiento gen \\
\hline & & FIP1L1-PDGFRA & $\begin{array}{l}\text { FIP1L1-PDGFR } \alpha \text { Fusión quinasa (o CHIC2 deleción) } \\
\text { positivo }\end{array}$ \\
\hline Imipramina & Psiquiatría & CYP2D6 & CYP2D6 Metabolizador pobre \\
\hline Indacaterol & Pulmonaria & UGT1A1 & UGT1A1-*28 alelo homocigoto \\
\hline Irinotecan & Oncología & UGT1A1 & UGT1A $1 * 28$ alelos portadores \\
\hline Hidralazina Isosorbida & Cardiología & NAT1-2 & Acetiladores lentos \\
\hline Ivacaftor & Pulmonaria & CFTR & $\begin{array}{l}\text { CFTR G551D, G1244E, G1349D, G178R, G551S, } \\
\text { S1251N, S1255P, S549N, o S549R mutación } \\
\text { transportador, F508 del mutación homocigotos }\end{array}$ \\
\hline Lansoprazol & Gastroenterología & CYP2C19 & CYP2C19 Metabolizador intermedio o pobre \\
\hline Lapatinib & Oncología & $\begin{array}{l}\text { ERBB2 } \\
\text { HLA-DQA1, } \\
\text { HLA-DRB1 }\end{array}$ & $\begin{array}{l}\text { HER2 Sobrexpresión proteína positiva } \\
\text { HLA-DQA1*0201 o DRB1*0701 alelo portador }\end{array}$ \\
\hline Lenalidomida & Hematología & $\operatorname{del}(5 q)$ & Cromosoma $5 q$ deleción positiva \\
\hline Letrozol & Oncología & ESR1, PGR & Receptor hormona positivo \\
\hline Lomitapida & Endocrinología & LDLR & LDLR mutación homocigoto \\
\hline Mafenida & Enfermedad infecciosa & G6PD & Deficiencia G6PD \\
\hline Mercaptopurina & Oncología & TPMT & TPMT Metabolizador intermedio o pobre \\
\hline Azul de Metileno & Hematología & G6PD & Deficiencia G6PD \\
\hline Metoclopramida & Gastroenterología & CYB5R1-4 & NADH deficiencia citocromo b5 reductasa \\
\hline Metoprolol & Cardiología & CYP2D6 & CYP2D6 Metabolizador pobre. \\
\hline
\end{tabular}


Tabla 5. Continuación

\begin{tabular}{|c|c|c|c|}
\hline Fármaco & Área terapéutica & Biomarcador & Subgrupo referencia \\
\hline Mipomersen & Endocrinología & LDLR & LDLR mutación heterocigotos y homocigotos \\
\hline Modafinilo & Psiquiatría & CYP2D6 & CYP2D6 Metabolizador pobre \\
\hline Ácido Micofenólico & Trasplantación & HPRT1 & Deficiencia HGPRT \\
\hline Ácido Nalidíxico & Enfermedad infecciosa & G6PD & Deficiencia G6PD \\
\hline Nefazodona & Psiquiatría & CYP2D6 & CYP2D6 Metabolizador pobre \\
\hline Nilotinib & Oncología & $\begin{array}{l}\text { BCR-ABL } \\
\text { UGT1A1 }\end{array}$ & $\begin{array}{l}\text { Cromosoma Filadelfia positivo } \\
\text { UGT1A } 1 * 28 \text { alelo homocigoto }\end{array}$ \\
\hline Nitrofurantoína & Enfermedad infecciosa & G6PD & Deficiencia G6PD \\
\hline Nortriptilina & Psiquiatría & CYP2D6 & CYP2D6 Metabolizador pobre \\
\hline Obinutuzumab & Oncología & MS4A1 & Antígeno CD20 positivo \\
\hline Omacetaxina & Oncología & BCR-ABL1 & Cromosoma Filadelfia positivo \\
\hline Omeprazol & Gastroenterología & CYP2C19 & CYP2C19 Metabolizador pobre \\
\hline Panitumumab & Oncología & $\begin{array}{l}\text { EGFR } \\
\text { KRAS }\end{array}$ & $\begin{array}{l}\text { EGFR Expresión proteína positiva } \\
\text { KRAS codón } 12 \text { y } 13 \text { mutación negativa }\end{array}$ \\
\hline Pantoprazol & Gastroenterología & CYP2C19 & CYP2C19 Metabolizador pobre \\
\hline Paroxetina & Psiquiatría & CYP2D6 & CYP2D6 Metabolizador extenso \\
\hline Pazopanib & Oncología & UGT1A1 & $\begin{array}{l}\text { UGT1A1*28 Alelo homocigoto } \\
\text { genotipo (TA)7/(TA)7 }\end{array}$ \\
\hline $\begin{array}{l}\text { PEG-3350, sulfato de sodio, } \\
\text { cloruro de sodio, cloruro de } \\
\text { potasio, ascorbato de sodio } \\
\text { y ácido ascórbico }\end{array}$ & Gastroenterología & G6PD & Deficiencia G6PD \\
\hline Pegloticasa & Reumatología & G6PD & Deficiencia G6PD \\
\hline Perfenazina & Psiquiatría & CYP2D6 & CYP2D6 Metabolizador pobre \\
\hline Pertuzumab & Oncología & ERBB2 & HER2 Sobreexpresión de proteína positiva \\
\hline Fenitonina & Neurología & HLA-B & HLA-B*1502 alelos portadores \\
\hline Pimozida & Psiquiatría & CYP2D6 & CYP2D6 Metabolizador pobre \\
\hline Ponatinib & Oncología & BCR-ABL1 & $\begin{array}{l}\text { Cromosoma Filadelfia positivo; T315I mutación } \\
\text { positiva }\end{array}$ \\
\hline Prasugrel & Cardiología & $\begin{array}{l}\text { CYP2C19 } \\
\text { CYP2C9 } \\
\text { CYP3A5 } \\
\text { CYP2B6 }\end{array}$ & $\begin{array}{l}\text { CYP2C19 Metabolizador pobre } \\
\text { CYP2C9 variante de transportadores } \\
\text { CYP3A5 variante de transportadores } \\
\text { CYP2B6 variante de transportadores }\end{array}$ \\
\hline Pravastatina & Endocrinología & LDLR & LDLR mutación homocigoto y heterocigotos \\
\hline Primaquina & Enfermedad infecciosa & G6PD & Deficiencia G6PD \\
\hline Propafenona & Cardiología & CYP2D6 & CYP2D6 Metabolizadores pobres \\
\hline Propranolol & Cardiología & CYP2D6 & CYP2D6 Metabolizadores pobres \\
\hline Protriptilina & Psiquiatría & CYP2D6 & CYP2D6 Metabolizadores pobres \\
\hline Quinidina & Cardiología & CYP2D6 & CYP2D6 Metabolizadores pobres \\
\hline Sulfato de Quinidina & Enfermedad infecciosa & $\begin{array}{l}\text { G6PD } \\
\text { CYP2D6 }\end{array}$ & $\begin{array}{l}\text { Deficiencia G6PD } \\
\text { CYP2D6 Metabolizadores pobres }\end{array}$ \\
\hline Rabeprazol & Gastroenterología & CYP2C19 & CYP2C19 Metabolizadores pobres \\
\hline Rasburicasa & Oncología & $\begin{array}{l}\text { G6PD } \\
\text { CYB5R1-4 }\end{array}$ & $\begin{array}{l}\text { Deficiencia G6PD } \\
\text { NADH Deficiencia citocromo b5 reductasa }\end{array}$ \\
\hline
\end{tabular}


Farmacogenómica, medicina personalizada y la práctica clínica - L. Quiñones et al

Tabla 5. Continuación

\begin{tabular}{|c|c|c|c|}
\hline Fármaco & Área terapéutica & Biomarcador & Subgrupo referencia \\
\hline $\begin{array}{l}\text { Rifampicina, Isoniazida, y } \\
\text { Pirazinamida }\end{array}$ & Enfermedad infecciosa & NAT1-2 & Acetiladores lentos \\
\hline Risperidona & Psiquiatría & CYP2D6 & CYP2D6 Metabolizadores pobres \\
\hline Rituximab & Oncología & MS4A1 & Antígeno CD20 positivo \\
\hline Simeprevir & Enfermedad infecciosa & IFNL3 & IL28B rs12979860 T alelo portador \\
\hline Nitrito de Sodio & Toxicología & G6PD & Deficiencia G6PD \\
\hline $\begin{array}{l}\text { Fenilacetato de Sodio } \\
\text { Benzoato de Sodio }\end{array}$ & $\begin{array}{l}\text { Erros intrínseco del } \\
\text { metabolismo }\end{array}$ & $\begin{array}{l}\text { nAGS, CPS1, } \\
\text { ASS1, OTC, } \\
\text { ASL, ABL2 }\end{array}$ & Ciclo deficiente de Ureasa \\
\hline Sofosbuvir & Enfermedad infecciosa & IFNL3 & $\begin{array}{l}\text { IL28B rs12979860 T Alelo portador } \\
\text { (non-C/C genotipo) IL28B }\end{array}$ \\
\hline Succimer & Hematología & G6PD & Deficiencia G6PD \\
\hline $\begin{array}{l}\text { Sulfametoxasol and } \\
\text { Trimetoprim }\end{array}$ & Enfermedad infecciosa & G6PD & Deficiencia G6PD \\
\hline Tamoxifeno & Oncología & $\begin{array}{l}\text { ESR1, PGR } \\
\text { F5 } \\
\text { F2 }\end{array}$ & $\begin{array}{l}\text { Receptor hormona positiva } \\
\text { Transportistas de Factor } V \text { Leiden } \\
\text { Protrombina } 20210 \text { Alelo positivo }\end{array}$ \\
\hline Telaprevir & Enfermedad infecciosa & IFNL3 & $\begin{array}{l}\text { IL28B rs12979860 T Alelo portador } \\
\text { (C/T and T/T genotipo) }\end{array}$ \\
\hline Terbinafina & Enfermedad infecciosa & CYP2D6 & CYP2D6 Metabolizador pobre \\
\hline Tetrabenazina & Neurología & CYP2D6 & CYP2D6 Metabolizador pobre \\
\hline Tioguanina & Oncología & TPMT & TPMT Metabolizador intermedio o pobre \\
\hline Tioridazina & Psiquiatría & CYP2D6 & CYP2D6 Metabolizador pobre \\
\hline Ticagrelor & Cardiología & CYP2C19 & CYP2C19 Metabolizador pobre \\
\hline Tolterodina & Genitourinaria & CYP2D6 & CYP2D6 Metabolizador pobre \\
\hline Tositumomab & Oncología & MS4A1 & Antígeno CD20 positivo \\
\hline Tramadol & Analgésica & CYP2D6 & CYP2D6 Metabolizador pobre \\
\hline Trametinib & Oncología & BRAF & BRAF V600E/K mutación positiva \\
\hline Trastuzumab & Oncología & ERBB2 & HER2 Sobrexpresión proteína positiva \\
\hline Tretinoina & Oncología & PML/RARA & PML/RAR $\alpha$ Translocación positiva \\
\hline Trimipramina & Psiquiatría & CYP2D6 & CYP2D6 Metabolizador pobre \\
\hline Ácido Valproico & Neurología & $\begin{array}{l}\text { POLG } \\
\text { NAGS, CPS1, } \\
\text { ASS1, OTC, } \\
\text { ASL, ABL2 }\end{array}$ & $\begin{array}{l}\text { POLG Mutación positiva } \\
\text { Ciclo deficiente ureasa }\end{array}$ \\
\hline Vemurafenib & Oncología & BRAF & BRAF V600E mutación positiva \\
\hline Venlafaxina & Psiquiatría & CYP2D6 & CYP2D6 Metabolizador pobre \\
\hline Voriconazol & Enfermedad infecciosa & CYP2C19 & CYP2C19 Metabolizador intermedio o pobre \\
\hline Vortioxetina & Neurología & CYP2D6 & CYP2D6 Metabolizador pobre \\
\hline Warfarina & $\begin{array}{l}\text { Cardiología o } \\
\text { hematología }\end{array}$ & $\begin{array}{l}\text { CYP2C9 } \\
\text { VKORC1 } \\
\text { PROS } \\
\text { PROC }\end{array}$ & $\begin{array}{l}\text { CYP2C9 Metabolizador intermedio o pobre } \\
\text { VKORC1 A Alelo portador } \\
\text { Deficiencia Proteína S } \\
\text { Deficiencia Proteína C }\end{array}$ \\
\hline
\end{tabular}


Tabla 6. Páginas web para el uso en farmacogenómica.

\begin{tabular}{|c|c|c|}
\hline Nombre & Tipo de Información & Link \\
\hline Drugbank & $\begin{array}{l}\text { Proporciona información general de fár- } \\
\text { macos }\end{array}$ & http://www.drugbank.ca/ \\
\hline PharmGKB & $\begin{array}{l}\text { Variantes genéticas, vías metabócias co- } \\
\text { nocidas, medicamentos afectados por el } \\
\text { polimorfismo, asociándolos a reacciones } \\
\text { adversas, entre otras }\end{array}$ & http://www.pharmgkb.org/ \\
\hline CPIC & $\begin{array}{l}\text { Genes polimórficos asociados a fármacos, } \\
\text { respaldado por guías científicas, aplicados } \\
\text { a la clínica }\end{array}$ & http://www.pharmgkb.org/page/cpic/ \\
\hline $\begin{array}{l}\text { FDA'spharmacogenetic } \\
\text { website }\end{array}$ & $\begin{array}{l}\text { Fármacos con sus etiquetas asociados a } \\
\text { biomarcadores genómicos, dosificaciones } \\
\text { para prevenir reacciones adversas, meca- } \\
\text { nismos de acción de los fármacos }\end{array}$ & $\begin{array}{l}\text { http://www.fda.gov/drugs/scienceresearch/ } \\
\text { researchareas/pharmacogenetics/ } \\
\text { ucm083378.html }\end{array}$ \\
\hline $\begin{array}{l}\text { Human Cytochrome P450 } \\
\text { Allele Nomenclature database }\end{array}$ & $\begin{array}{l}\text { Clasificación alélica súper familia CYP450, } \\
\text { relación fenotipo y genotipo, entre otros }\end{array}$ & http://www.cypalleles.ki.se/ \\
\hline $\begin{array}{l}\text { Cytochrome P450 Drug } \\
\text { Interaction Table }\end{array}$ & $\begin{array}{l}\text { Interacción entre fármacos/enzimas familia } \\
\text { CYP450 }\end{array}$ & $\begin{array}{l}\text { http://medicine.iupui.edu/clinpharm/ddis/ } \\
\text { clinical-table/ }\end{array}$ \\
\hline 1000 genomes browser & $\begin{array}{l}\text { Buscador de los resultados del proyecto } \\
1000 \text { genomas, variantes genéticas en las } \\
\text { diferentes poblaciones humanas }\end{array}$ & http://browser.1000genomes.org/index.html \\
\hline NAT-allele database & $\begin{array}{l}\text { Nomenclatura de las variantes en transpor- } \\
\text { tadores NAT }\end{array}$ & http://nat.mbg.duth.gr/ \\
\hline UGT-allele database & Nomenclatura alélica de UGTs & $\begin{array}{l}\text { http://www.pharmacogenomics.pha.ulaval. } \\
\text { ca/sgc/ugt_alleles }\end{array}$ \\
\hline PACdb & $\begin{array}{l}\text { Información acerca de la farmacología, ex- } \\
\text { presión genética, obteniendo datos a tra- } \\
\text { vés de líneas celulares linfoblastoides (LCL) }\end{array}$ & http://www.pacdb.org/ \\
\hline SCANdb & Registros de SNPs y estudios GWAS & http://www.scandb.org/ \\
\hline GWAS catalog & $\begin{array}{l}\text { Base de datos con estudios GWAS que } \\
\text { incluye filtros y resultados resumidos }\end{array}$ & http://www.ebi.ac.uk/gwas/home \\
\hline dbSNP & $\begin{array}{l}\text { Base de datos del NCBI y variaciones pe- } \\
\text { queñas }\end{array}$ & http://www.ncbi.nlm.nih.gov/SNP/ \\
\hline dbVar & $\begin{array}{l}\text { Base de datos del NCBI y variaciones es- } \\
\text { tructurales grandes }\end{array}$ & http://www.ncbi.nlm.nih.gov/dbvar \\
\hline HGNC & $\begin{array}{l}\text { Base de datos que incluye los símbolos y } \\
\text { nombres únicos aprobados en genética } \\
\text { humana para genes y sus variantes ge- } \\
\text { néticas }\end{array}$ & http://www.genenames.org/ \\
\hline Clinicaltrials.gov & $\begin{array}{l}\text { Base de datos de estudios clínicos. Incluye } \\
\text { estudios farmacogenómicos asociados }\end{array}$ & https://clinicaltrials.gov/ \\
\hline MedGen & $\begin{array}{l}\text { Base de datos en genética humana que } \\
\text { incluye información de medicamentos y } \\
\text { estudios clínicos }\end{array}$ & http://www.ncbi.nlm.nih.gov/medgen \\
\hline GWAS db v2 & $\begin{array}{l}\text { Base de datos de los resultados más rele- } \\
\text { vantes en los estudios GWAS }\end{array}$ & http://jjwanglab.org/gwasdb \\
\hline
\end{tabular}

SNP: Single nucleotide polymorphism; GWAS: genome wide-association studies; HGNC: Human genome nomenclature commitee; PACdb: Pharmacogenomics And Cell database; CPIC: Clinical Pharmacogenomic Implementation Consortium. CYP450: citocromo P450. NAT: N-acetiltransferasas. UGT: Uridin difosfato glucuroniltransferasas. 
La utilidad de la farmacogenómica ha sido evidenciada en estudios realizados en pacientes con trastornos depresivos, los cuales al ser ajustada la dosis del medicamento en relación a su perfil genómico obtuvieron mejor eficacia y menores reacciones adversas ${ }^{57,58}$. Del mismo modo, se han obtenido resultados beneficiosos al incluir pruebas farmacogenómicas en esquemas de dosificación de oxicodona/CYP2D6 ${ }^{59}$, isoniazida/NAT2 $2^{60}$, clopidogrel/CYP2C1961, 5-FU/DPD ${ }^{62}$, voriconazol/ CYP2C19 $9^{63}$ y warfarina/CYP2C9-VKORC1 ${ }^{64}$.

\section{Discusión}

La investigación farmacogenómica persigue predecir la respuesta del paciente a la farmacoterapia y, posteriormente, adaptar la estrategia posológica. En este aspecto, se estima que los polimorfismos genéticos dan cuenta de $20 \%$ de la respuesta a algunos medicamentos y para otros hasta de $95 \%{ }^{1}$. De todos los fármacos conocidos que generan reacciones adversas conocidas, sobre el $80 \%$ se metaboliza por enzimas polimórficas ${ }^{22}$. Al respecto, a partir de 2004, varios medicamentos incluyen información farmacogenética en sus fichas técnicas con datos suficientes para guiar decisiones en el tratamiento ${ }^{65}$. En 2005, la FDA emitió un documento de orientación para la industria sobre los datos de referencia para la determinación del genotipo en enzimas y en el mismo año aprobó la comercialización del primer test farmacogenético de laboratorio basado en genotipos del citocromo $\mathrm{P} 450^{66}$. Sin embargo, en América Latina la prueba parece no tener resultados óptimos, lo que podría deberse a las diferencias étnicas.

Por lo tanto, el desafío actual para la terapia personalizada es definir perfiles genéticos individuales y poblacionales para predecir la respuesta a los fármacos y la progresión de las enfermedades $^{21,25,67-69}$. La información para hacer frente a este reto sólo puede obtenerse a partir de estudios casos/control y/o estudios prospectivos con base farmacogenómica.

A pesar de la enorme cantidad de información conocida, la aceptación de los estudios farmacogenómicos y su aplicación práctica médica ha sido gradual. Varias cuestiones han impedido su rápida aplicación, tales como: a) falta de laboratorios clínicos disponibles para realizar estas pruebas de forma rápida y costo-efectiva; b) escasez de profesionales de la salud que puedan interpretar los resultados de las pruebas y la farmacología clínica asociada y c) dudas sobre si las compañías de seguros o sistemas de salud podrán subsidiar estas pruebas. Además, muchas preguntas éticas plantean desafíos a analizar.

Por supuesto que la farmacogenómica tiene varias limitaciones para ser aplicada en la práctica clínica y que deben abordarse. Algunas de estas limitaciones han sido analizadas previamente ${ }^{25}$ e incluyen la falta de análisis costo-efectividad, necesidad de identificación de nuevos biomarcadores de toxicidad de medicamentos y su respuesta, limitaciones técnicas y variaciones étnicas. Adicionalmente, sabemos que existe variabilidad por factores no genéticos, dando lugar a la idea de que la farmacogenómica es sólo uno de los varios factores a considerar en el ajuste de la dosis. Por lo tanto, algoritmos que incluyan factores no genómicos y ambientales parecen ser el mejor enfoque.

Otra restricción para el uso de la farmacogenómica es la escasa información sobre pharmagenes (genes farmacogenómicos) en las poblaciones de América Latina, lo que impide la extrapolación directa desde estudios clínicos realizados en otros grupos étnicos. Entonces, es evidente que hay una necesidad de desarrollar más estudios y mejor diseñados, en nuestra región. Estos estudios deben incluir la comparación étnica de perfiles farmacogenómicos, el impacto del polimorfismo en el fenotipo, los perfiles metabólicos de pacientes tratados con un determinado fármaco y factores ambientales relevantes que influyen en la respuesta a los fármacos.

Antes de la aplicación de pharmagenes en la clínica, los profesionales de la salud (prescriptores, aseguradores y reguladores) querrán saber si hay un impacto sustancial de la farmacogenómica sobre la seguridad y eficacia del fármaco en un individuo. El desarrollo de guías de práctica clínica y protocolos específicos de base farmacogenómica puede ayudar a superar las principales barreras y limitaciones así como también el apoyo gubernamental.

En resumen, hoy en día los tratamientos individualizados son una necesidad apremiante. La fórmula actual de farmacoterapia estándar no considera de forma adicional la gran variabilidad entre los pacientes.

La integración de la farmacogenómica en la práctica clínica requiere, sin embargo, capacitación a profesionales de salud y a la ciudadanía, además de directrices, garantías legales y reglamentarias. La 
respuesta a la pregunta de qué paciente debe recibir qué fármaco y la dosis a utilizar en cada caso no será nada fácil, pero creemos que el enfoque ofrecido por la farmacogenómica se debe incorporar en el proceso de toma de decisiones. Un uso más racional de medicamentos, junto con acciones para minimizar los eventos tóxicos a los pacientes y sus consecuencias, reduciría drásticamente los costos médicos, como un beneficio adicional. Por lo tanto, esta disciplina se transforma en un eje relevante de la medicina personalizada ${ }^{18,20}$.

Agradecimientos: Este trabajo ha sido configurado gracias al apoyo financiero de la Comisión Nacional Cientifica y Tecnológica (CONICYT) a través del proyecto Fondecyt Regular 1140434 y está patrocinado por la Sociedad Latinoamericana de Farmacogenómica y Medicina Personalizada (SOLFAGEM).

\section{Referencias}

1. Evans WE, McLeod HL. Pharmacogenomics-drug disposition, drug targets, and side effects. N Engl J Med. 2003; 348 (6): 538-49.

2. Zhou S-F, Di YM, Chan E, Du Y-M, Chow VD-W, Xue CC, et al. Clinical pharmacogenetics and potential application in personalized medicine. Curr Drug Metab 2008; 9 (8): 738-84.

3. Wijnen PAHM, Op den Buijsch RAM, Drent M, Kuijpers PMJC, Kuipers PMJC, Neef C, et al. Review article: The prevalence and clinical relevance of cytochrome P450 polymorphisms. Aliment Pharmacol Ther 2007; 26 Suppl 2: 211-9.

4. Guideline on key aspects for the use of pharmacogenomics in the pharmacovigilance of medicinal products, European Medicines Agency. WC500196800. p15. (2015).

5. Deenen MJ, Cats A, Beijnen JH, Schellens JHM. Part 1: background, methodology, and clinical adoption of pharmacogenetics. Oncologist 2011; 16 (6): 811-9.

6. Ma Q, Lu AYH. Pharmacogenetics, pharmacogenomics, and individualized medicine. Pharmacol Rev 2011; 63 (2): 437-59.

7. The Genome project [Internet]. National Human Genome Research Institute. [actualizado: 1 de octubre de 2015; citado 20 de mayo de 2016]. Disponible en: http:// www.genome.gov/10001772.

8. International HapMap Project [Internet]. [citado $20 \mathrm{de}$ Mayo de 2016]. Disponible en: http://hapmap.ncbi.nlm. nih.gov/index.html.en.

9. Thorisson GA, Stein LD. The SNP Consortium website: past, present and future. Nucleic Acids Res 2003; 31 (1): 124-7.

10. Gwas Catalog [Internet]. EMBL-EBI. [c2015; citado 20 de Mayo de 2016]. Disponible en: http://www.ebi.ac.uk/ gwas/>.

11. Innocenti F, Cox NJ, Dolan ME. The use of genomic information to optimize cancer chemotherapy. Semin Oncol 2011; 38 (2): 186-95.

12. Simon R, Roychowdhury S. Implementing personalized cancer genomics in clinical trials. Nat Rev Drug Discov 2013; 12 (5): 358-69.

13. Ensembl [Internet]. EMBL-EBI. [c2016; citado el 20 de mayo de 2016]. Disponible en: http://www.ensembl.org/ Homo_sapiens/Location/Genome.

14. Clinical Pharmacogenetics Implementation Consortium. PharmGkb [Internet]. [citado el 20 de mayo de 2016]. Disponible en: https://www.pharmgkb.org/page/cpic

15. Vogel F. Moderne Problema der Humangenetik. Ergebn. Posada. Med Kinderheilkd 1959; 12: 52-125.

16. Quinones LA, Lavanderos MA, Cayun JP, Garcia-Martin E, Agundez JA, Caceres DD, et al. Perception of the usefulness of drug/gene pairs and barriers for pharmacogenomics in Latin America. Curr Drug Metab 2014; 15 (2): 202-8.

17. Kiyotani K, Uno S, Mushiroda T, Takahashi A, Kubo $\mathrm{M}$, Mitsuhata N, et al. A genome-wide association study identifies four genetic markers for hematological toxicities in cancer patients receiving gemcitabine therapy. Pharmacogenet Genomics 2012; 22 (4): 229-35.

18. Lee MTM, Mahasirimongkol S, Zhang Y, Suwankesawong W, Chaikledkaew U, Pavlidis C, et al. Clinical application of pharmacogenomics: the example of HLA-based drug-induced toxicity. Public Health Genomics 2014; 17 (5-6): 248-55.

19. Redekop WK, Mladsi D. The faces of personalized medicine: a framework for understanding its meaning and scope. Value Health; 16 (6 Suppl): S4-9.

20. Hunt LM, Kreiner MJ. Pharmacogenetics in primary care: the promise of personalized medicine and the reality of racial profiling. Cult Med Psychiatry 2013; 37 (1): 226-35.

21. Gladding PA. Clinical applications of pharmacogenetics: present and near future. Cleve Clin J Med 2013; 80 (8): 477-82.

22. Phillips KA, Veenstra DL, Oren E, Lee JK, Sadee W. Potential role of pharmacogenomics in reducing adverse drug reactions: a systematic review. JAMA 2001; 286 (18): 2270-9.

23. Martin MA, Hoffman JM, Freimuth RR, Klein TE, Dong BJ, Pirmohamed M, et al. Clinical Pharmacogenetics Implementation Consortium Guidelines for HLA-B 
Genotype and Abacavir Dosing: 2014 update. Clin Pharmacol Ther 2014; 95 (5): 499-500.

24. Crews KR, Hicks JK, Pui C-H, Relling MV, Evans WE. Pharmacogenomics and individualized medicine: translating science into practice. Clin Pharmacol Ther 2012; 92 (4): 467-75.

25. Agúndez JAG, Abad-Santos F, Aldea A, Alonso-Navarro H, Bernal ML, Borobia AM, et al. Toward a clinical practice guide in pharmacogenomics testing for functional polymorphisms of drug-metabolizing enzymes. Gene/drug pairs and barriers perceived in Spain. Front Genet 2012; 3: 273.

26. Roco Á, Quiñones L, Agúndez JAG, García-Martín E, Squicciarini V, Miranda C, et al. Frequencies of 23 functionally significant variant alleles related with metabolism of antineoplastic drugs in the Chilean population : comparison with Caucasian and Asian populations. 2012; 3: 1-9.

27. Spear BB, Heath-Chiozzi M, Huff J. Clinical application of pharmacogenetics. Trends Mol Med 2001; 7 (5): 201-4.

28. Quiñones L, Lee K, Varela FN, Escala M, García K, Godoy L, et al. [Cancer pharmacogenetics: study of genetically determined variations on cancer susceptibility due to xenobiotic exposure]. Rev Med Chile 2006; 134 (4): 499-515.

29. Cypalleles.ki.se [Internet]. The Human Cytochrome P450 (CYP) Allele Nomenclature Database [citado el 20 de mayo de 2016]. Disponible en: http://www.cypalleles. ki.se

30. Kalman LV, Agúndez J, Appell ML, Black JL, Bell GC, Boukouvala $S$, et al. Pharmacogenetic allele nomenclature: International workgroup recommendations for test result reporting. Clin Pharmacol Ther 2016; 99 (2): 172-85.

31. Weinshilboum R. Inheritance and drug response. $\mathrm{N}$ Engl J Med 2003; 348 (6): 529-37.

32. Umamaheswaran G, Kumar DK, Adithan C. Distribution of genetic polymorphisms of genes encoding drug metabolizing enzymes \& drug transporters-a review with Indian perspective. Indian J Med Res 2014; 139 (1): 27-65.

33. Jancova P, Anzenbacher P, Anzenbacherova E. Phase II drug metabolizing enzymes. Biomed Pap Med Fac Univ Palacký, Olomouc, Czechoslov 2010; 154 (2): 103-16.

34. Yiannakopoulou EC. Pharmacogenomics of phase II metabolizing enzymes and drug transporters: clinical implications. Pharmacogenomics J 2013; 13 (2): 105-9.

35. Varela N, Quiñones LA, Stojanova J, Garay J, Cáceres D, Cespedes S, et al. Characterization of the CYP2D6 drug metabolizing phenotypes of the Chilean mestizo population through polymorphism analyses. Pharmacol
Res 2015; 101: 124-9.

36. Ingelman-Sundberg M. Pharmacogenetics: an opportunity for a safer and more efficient pharmacotherapy. J Intern Med 2001; 250 (3): 186-200.

37. Rodríguez-Antona C, Ingelman-Sundberg M. Cytochrome P450 pharmacogenetics and cancer. Oncogene 2006; 25 (11): 1679-91.

38. Huang B, Jiang C, Zhang R. Epigenetics: the language of the cell? Epigenomics 2014; 6 (1): 73-88.

39. Yu A-M, Tian Y, Tu M-J, Ho PY, Jilek JL. MicroRNA Pharmacoepigenetics: Posttranscriptional Regulation Mechanisms behind Variable Drug Disposition and Strategy to Develop More Effective Therapy. Drug Metab Dispos 2016; 44 (3): 308-19.

40. Cheok MH, Evans WE. Acute lymphoblastic leukaemia: a model for the pharmacogenomics of cancer therapy. Nat Rev Cancer 2006; 6 (2): 117-29.

41. Johnson JA, Gong L, Whirl-Carrillo M, Gage BF, Scott SA, Stein CM, et al. Clinical Pharmacogenetics Implementation Consortium Guidelines for CYP2C9 and VKORC1 genotypes and warfarin dosing. Clin Pharmacol Ther 2011; 90 (4): 625-9.

42. da Silva Nogueira J, de Lima Marson FA, Sílvia Bertuzzo C. Thymidylate synthase gene (TYMS) polymorphisms in sporadic and hereditary breast cancer. BMC Res Notes 2012; 5: 676.

43. Rosmarin D, Palles C, Pagnamenta A, Kaur K, Pita G, Martin M, et al. A candidate gene study of capecitabine-related toxicity in colorectal cancer identifies new toxicity variants at DPYD and a putative role for ENOSF1 rather than TYMS. Gut 2015; 64 (1): 111-20.

44. 1000 Genomes Project [Internet]. [c2015; citado el 20 de mayo de 2016]. Disponible en: http://browser.1000genomes.org/index.html

45. Kimchi-Sarfaty C, Oh JM, Kim I-W, Sauna ZE, Calcagno AM, Ambudkar S V, et al. A "silent" polymorphism in the MDR1 gene changes substrate specificity. Science 2007; 315 (5811): 525-8.

46. Vulsteke C, Lambrechts D, Dieudonné A, Hatse S, Brouwers B, van Brussel T, et al. Genetic variability in the multidrug resistance associated protein-1 (ABCC1/ MRP1) predicts hematological toxicity in breast cancer patients receiving (neo-)adjuvant chemotherapy with 5-fluorouracil, epirubicin and cyclophosphamide (FEC). Ann Oncol 2013; 24 (6): 1513-25.

47. Xu G, Bhatnagar V, Wen G, Hamilton BA, Eraly SA, Nigam SK. Analyses of coding region polymorphisms in apical and basolateral human organic anion transporter (OAT) genes [OAT1 (NKT), OAT2, OAT3, OAT4, URAT (RST)]. Kidney Int 2005; 68 (4): 1491-9.

48. Chen Y, Li S, Brown C, Cheatham S, Castro RA, 
Leabman MK, et al. Effect of genetic variation in the organic cation transporter 2 on the renal elimination of metformin. Pharmacogenet Genomics 2009; 19 (7): 497-504.

49. Bruhn O, Cascorbi I. Polymorphisms of the drug transporters $\mathrm{ABCB} 1, \mathrm{ABCG} 2, \mathrm{ABCC} 2$ and $\mathrm{ABCC} 3$ and their impact on drug bioavailability and clinical relevance. Expert Opin Drug Metab Toxicol 2014; 10 (10): 1337 54.

50. Zhou Z-W, Chen X-W, Sneed KB, Yang Y-X, Zhang X, $\mathrm{He} Z$-X, et al. Clinical association between pharmacogenomics and adverse drug reactions. Drugs 2015; 75 (6): 589-631.

51. Food and Drug Administration [Internet]. Table of Pharmacogenomic Biomarker in Drug Labeling. [actualizado el 20 de mayo de 2015, citado el 20 de mayo de 2016]. Disponible en: http://www.fda.gov/Drugs/ ScienceResearch/ResearchAreas/Pharmacogenetics/ ucm083378.htm

52. Ghaddar F, Cascorbi I, Zgheib NK. Clinical implementation of pharmacogenetics: a nonrepresentative explorative survey to participants of WorldPharma 2010. Pharmacogenomics 2011; 12 (7): 1051-9.

53. Gillis NK, Innocenti F. Evidence required to demonstrate clinical utility of pharmacogenetic testing: the debate continues. Clin Pharmacol Ther 2014; 96 (6): 655-7.

54. Ramos E, Doumatey A, Elkahloun AG, Shriner D, Huang H, Chen G, et al. Pharmacogenomics, ancestry and clinical decision making for global populations. Pharmacogenomics J 2014; 14 (3): 217-22.

55. Stanek EJ, Sanders CL, Taber KAJ, Khalid M, Patel A, Verbrugge RR, et al. Adoption of pharmacogenomic testing by US physicians: results of a nationwide survey. Clin Pharmacol Ther 2012; 91 (3): 450-8.

56. Caudle KE, Klein TE, Hoffman JM, Muller DJ, Whirl-Carrillo M, Gong L, et al. Incorporation of pharmacogenomics into routine clinical practice: the Clinical Pharmacogenetics Implementation Consortium (CPIC) guideline development process. Curr Drug Metab [Internet] 2014; 15 (2): 209-17 [citado el 19 de abril de 2016].

57. Brennan FX, Gardner KR, Lombard J, Perlis RH, Fava M, Harris HW, et al. A Naturalistic Study of the Effectiveness of Pharmacogenetic Testing to Guide Treatment in Psychiatric Patients With Mood and Anxiety Disorders. Prim care companion CNS Disord 2015; 17 (2).

58. Hicks JK, Swen JJ, Thorn CF, Sangkuhl K, Kharasch ED, Ellingrod VL, et al. Clinical Pharmacogenetics Implementation Consortium guideline for CYP2D6 and CYP2C19 genotypes and dosing of tricyclic antidepressants. Clin Pharmacol Ther 2013; 93 (5): 402-8.
59. Linares OA, Daly D, Linares AD, Stefanovski D, Boston RC. Personalized oxycodone dosing: using pharmacogenetic testing and clinical pharmacokinetics to reduce toxicity risk and increase effectiveness. Pain Med 2014; 15 (5): 791-806.

60. Azuma J, Ohno M, Kubota R, Yokota S, Nagai T, Tsuyuguchi $\mathrm{K}$, et al. NAT2 genotype guided regimen reduces isoniazid-induced liver injury and early treatment failure in the 6-month four-drug standard treatment of tuberculosis: a randomized controlled trial for pharmacogenetics-based therapy. Eur J Clin Pharmacol 2013; 69 (5): 1091-101.

61. Mega JL, Hochholzer W, Frelinger AL, Kluk MJ, Angiolillo DJ, Kereiakes DJ, et al. Dosing clopidogrel based on CYP2C19 genotype and the effect on platelet reactivity in patients with stable cardiovascular disease. JAMA 2011; 306 (20): 2221-8.

62. Yang CG, Ciccolini J, Blesius A, Dahan L, Bagarry-Liegey D, Brunet C, et al. DPD-based adaptive dosing of 5-FU in patients with head and neck cancer: impact on treatment efficacy and toxicity. Cancer Chemother Pharmacol 2011; 67 (1): 49-56.

63. Teusink A, Vinks A, Zhang K, Davies S, Fukuda T, Lane A, et al. Genotype-Directed Dosing Leads to Optimized Voriconazole Levels in Pediatric Patients Receiving Hematopoietic Stem Cell Transplantation. Biol Blood Marrow Transplant 2016; 22 (3): 482-6.

64. Pirmohamed M, Burnside G, Eriksson N, Jorgensen AL, Toh CH, Nicholson T, et al. A randomized trial of genotype-guided dosing of warfarin. N Engl J Med 2013; 369 (24): 2294-303.

65. Zineh I, Gerhard T, Aquilante CL, Beitelshees AL, Beasley BN, Hartzema AG. Availability of pharmacogenomics-based prescribing information in drug package inserts for currently approved drugs. Pharmacogenomics J 2004; 4 (6): 354-8.

66. Rebsamen MC, Desmeules J, Daali Y, Chiappe A, Diemand A, Rey C, et al. The AmpliChip CYP450 test: cytochrome P450 2D6 genotype assessment and phenotype prediction. Pharmacogenomics J 2009; 9 (1): 34-41.

67. Agúndez JAG, Del Barrio J, Padró T, Stephens C, Farré $\mathrm{M}$, Andrade RJ, et al. Trends in qualifying biomarkers in drug safety. Consensus of the 2011 meeting of the spanish society of clinical pharmacology. Front Pharmacol 2012; 3: 2.

68. Gardiner SJ, Begg EJ. Pharmacogenetics, drug-metabolizing enzymes, and clinical practice. Pharmacol Rev 2006; 58 (3): 521-90.

69. Gurwitz D, Lunshof JE. Personalized pharmacotherapy: genotypes, biomarkers, and beyond. Clin Pharmacol Ther 2009; 85 (2): 142. 